\title{
Use of sugammadex in a patient with Charcot-Marie- Tooth disease under general anesthesia
}

\author{
Naoki Itoh ${ }^{1}$, Hiroshi Hoshijima ${ }^{1}$, Risa Takeuchi' ${ }^{1}$, China Nakamura ${ }^{1}$, Yoshinori Iwase ${ }^{1}$, Hiroshi Nagasaka', \\ Tsuyoshi Sato², Tetsuya Yoda² \\ 'Department of Anesthesiology, Faculty of Medicine, Saitama Medical University Hospital, Saitama 350-0495, Japan. \\ 2Department of Oral and Maxillofacial Surgery, Faculty of Medicine, Saitama Medical University Hospital, Saitama 350-0495, Japan.
}

Correspondence to: Dr. Hiroshi Hoshijima, Department of Anesthesiology, Faculty of Medicine, Saitama Medical University Hospital, 38 Morohongo, Moroyama-machi, Iruma-gun, Saitama 350-0495, Japan. E-mail: hhoshi@saitama-med.ac.jp

\begin{abstract}
How to cite this article: Itoh N, Hoshijima H, Takeuchi R, Nakamura C, Iwase Y, Nagasaka H, Sato T, Yoda T. Use of sugammadex in a patient with Charcot-Marie-Tooth disease under general anesthesia. Stomatological Dis Sci2018;2:2.
\end{abstract}

http://dx.doi.org/10.20517/2573-0002.2017.14

Received: 4 Sep 2017 First Decision: 31 Jan 2018 Revised: 6 Feb 2018 Accepted: 16 Feb 2018 Published: 27 Feb 2018

Science Editor: Nikolaos G. Nikitakis Copy Editor: Jun-Yao Li Prduction Editor: Huan-Liang Wu

\begin{abstract}
Charcot-Marie-Tooth disease (CMT) is an inherited heterogeneous group of peripheral nerve disorders with characterized by weakness and sensory loss in the distal limbs. General anesthesia was induced with propofol, rocuronium, and remifentanil. At the end of the surgery, we administered a total of $150 \mathrm{mg}$ sugammadex. The patient could lift his head and arms, open his eyes. Then we extubated tracheal tube. We successfully used sugammadex in a patient with CMT to reverse rocuronium-induced neuromuscular blockade. However, muscle relaxation might not be measured accurately in CMT patients. Thus, clinical findings should be referred to in the management of anesthesia.
\end{abstract}

Keywords: Sugammadex, Charcot-Marie-Tooth disease, anesthesia

\section{INTRODUCTION}

Charcot-Marie-Tooth (CMT) disease is the most common inherited neuromuscular disease, with typical onset during the first or second decade and associated with lifelong disability. CMT disease results from mutations in about 80 causative genes giving rise to a wide spectrum of clinical phenotypes, with different age of onset and clinical course ${ }^{[1]}$. The estimated worldwide incidence of CMT is $10-40$ per 100,000 people worldwide and at 10.8 people per 100,000 people in Japan ${ }^{[2]}$. Most patients with CMT have a normal lifespan, but some patients with a very severe disease might have a very short lifespan because they are nonambulatory and because the profound weakness of proximal and distal muscles can lead to pulmonary dysfunction or sleep disorders ${ }^{[3]}$. Patients with CMT also develop progressive disability with increasing age,

Cc) (i) The Author(s) 2018. Open Access This article is licensed under a Creative Commons Attribution 4.0 International License (https://creativecommons.org/licenses/by/4.0/), which permits unrestricted use, sharing, adaptation, distribution and reproduction in any medium or format, for any purpose, even commercially, as long as you give appropriate credit to the original author(s) and the source, provide a link to the Creative Commons license, and indicate if changes were made. 


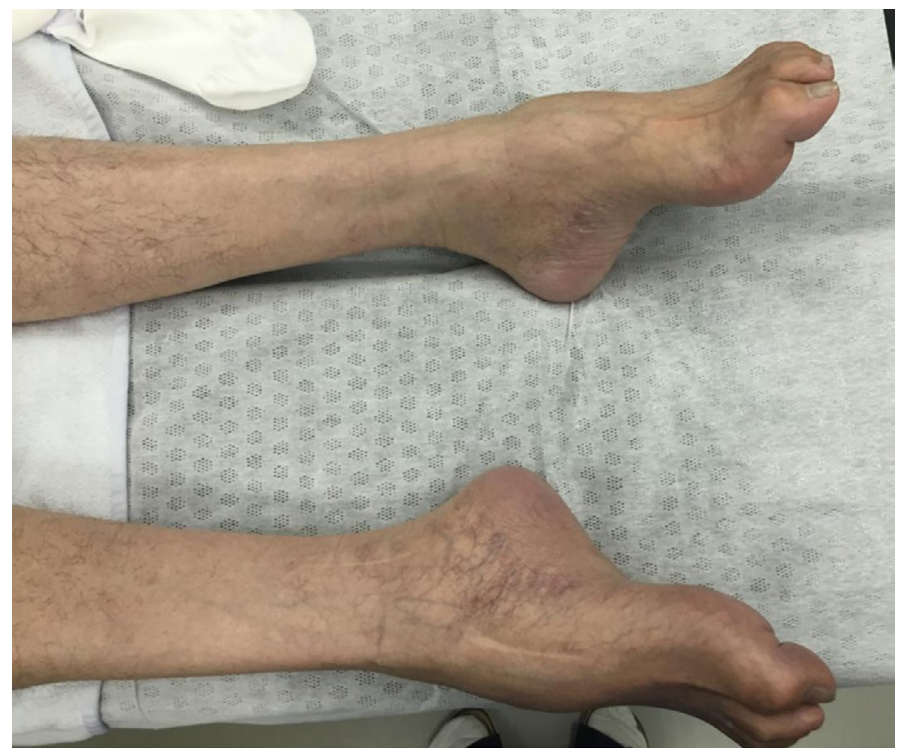

Figure 1. Photograph of a pes cavus foot deformity

so the clinical manifestations usually begin in the second decade of life, but some patients develop CMT after the age of 60 years. Initial symptoms include muscle weakness and sensory disturbance, especially in the lower limbs. CMT is associated with various genetic anomalies that lead to different types of complications including vocal cord paralysis, features of autonomic neuropathy (urinary disorders, dry cough, and pupillary abnormalities), visual disturbance, disturbance of the pyramidal tract, diabetes, and dyslipidemia. Severe cases may progress to respiratory failure, sometimes requiring mechanical ventilation ${ }^{[4]}$. Consequently, CMT requires more stringent management of anesthesia, especially regarding monitoring of muscle weakness.

Sugammadex, a novel modified $\gamma$-cyclodextrin, encapsulates steroidal neuromuscular blocking drugs, thereby reversing rocuronium-induced neuromuscular block. Several cases series of anesthetic reports on the general anesthetic management of patients with CMT have been published. Of these, only one reported the use of sugammadex in the reversal of rocuronium in laparoscopic cholecystectomy surgery ${ }^{\left[{ }^{[5]}\right.}$. However, there are no reports on the use of sugammadex for patients with CMT in the field of oral and maxillofacial surger ${ }^{[6-8]}$.

We report the successful use of sugammadex to reverse rocuronium-induced neuromuscular block in a patient with CMT in the field of oral and maxillofacial surgery.

\section{CASE REPORT}

A 60-year-old male patient with CMT, weighing $67.8 \mathrm{~kg}$ and $170.8 \mathrm{~cm}$ tall, was scheduled for surgical extraction of the mandibular right second molar and the mandibular right impacted third molar. He first noticed muscle weakness in the lower limbs at the age of 16 years and observed gait disturbance and weakness in both legs at the age of 42 years. He was first diagnosed with CMT at 51 years of age. On preoperative physical examination, his CMT symptoms were mainly those of an abnormal gait [Figure 1]. An abnormal gait is a typical symptom of CMT. A severe complication of CMT is respiratory failure. However, he did not have any respiratory symptoms at the time, and preoperative respiratory function tests were within normal range. Preoperative blood tests, electrocardiography, and chest X-ray were all normal. There were no other complications such as vocal cord paralysis, autonomic neuropathy (urinary disorders, dry cough, and pupillary abnormalities), visual disturbance, disturbance of the pyramidal tract, diabetes, and dyslipidemia. He was assigned an American Society of Anesthesiologists physical status of II. 


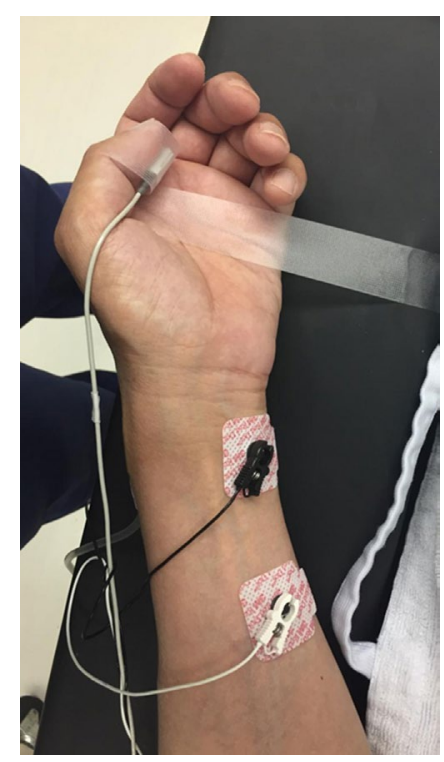

Figure 2. The peripheral nerve stimulator was applied to the left ulnar nerve

The patient was not pre-medicated and was monitored with electrocardiography, noninvasive blood pressure, and pulse oximetry. A neuromuscular monitoring device was placed on the left wrist and calibrated using the objective evoked electromyography of the adductor pollicis muscle using a TOF-Watch ${ }^{\circledR}$ SX (Organon ${ }^{\circledR}$, Oss, The Netherlands) [Figure 2]. Following pre-oxygenation, general anesthesia was induced with propofol $80 \mathrm{mg}$ and remifentanil $0.50 \mu \mathrm{g} / \mathrm{kg} / \mathrm{min}$. After the loss of consciousness, neuromuscular monitoring was performed by evoked electromyography of the adductor pollicis muscle. The left ulnar nerve was stimulated at the wrist with supra-maximal and square-wave stimuli of $0.2 \mathrm{~ms}$ duration, $2 \mathrm{~Hz}$ every $15 \mathrm{~s}$. The fade was not detected before the administration of rocuronium $40 \mathrm{mg}$ IV. After induction of anesthesia, the train-offour (TOF) ratio was indicated as 0 . We performed tracheal intubation with no complications. Anesthesia was maintained uneventfully with remifentanil $0.2 \mu \mathrm{g} / \mathrm{kg} / \mathrm{min}$ and desflurane $5 \%$ in oxygen and air.

During the operation, $105 \mathrm{~min}$ after the administration of rocuronium, the anesthesiologist could detect a T1 response. Before the end of the operation, acetaminophen $(1000 \mathrm{mg})$ was administered for postoperative analgesia. Desflurane inhalation and remifentanil infusion were terminated at the end of the surgery by which time we could detect a T2 response. After the neuromuscular monitoring indicated a sustained T2 response, we administered $50 \mathrm{mg}$ sugammadex. Within $180 \mathrm{~s}$ of administration of sugammadex, we detected a $\mathrm{T} 4$ response $(\mathrm{T} 4 / \mathrm{T} 1=4.0)$. We administered another $100 \mathrm{mg}$ sugammadex, and could no longer detect a fade. The patient could lift his head and arms, open his eyes, and protrude his tongue. Consequently, we extubated the patient $15 \mathrm{~min}$ after administration of sugammadex. The postoperative course was uneventful, and no respiratory complications were observed.

\section{DISCUSSION}

We successfully used sugammadex in a patient with CMT to reverse rocuronium-induced neuromuscular blockade in the field of oral and maxillofacial surgery. However, because the muscle relaxation might not be accurately measured in CMT patients, the management of anesthesia should refer to clinical findings.

There is no consensus on the management of anesthesia in patients with $\mathrm{CMT}^{[9]}$. Also known as peripheral nerve disorder, the disease is characterized by progressive muscle atrophy and weakness that initially develops in the anterior tibial and peroneal muscles and later progresses to involve the more distal muscles. The weakness of the proximal and distal muscles can lead to pulmonary or upper airway disturbances. 
Therefore, patients should be carefully observed during recovery from neuromuscular blockade under general anesthesia.

Before the development of sugammadex, cholinesterase inhibitors were the only option for the reversal of neuromuscular block. Modified $\gamma$-cyclodextrinsugammadex has been available in Japan since 2010. The intravascular encapsulating mechanism of action, distant from the neuromuscular junction, suggests that it should be ideal for reversing both superficial and deep levels of a neuromuscular block ${ }^{[10]}$. The balance of acetylcholine in the neuromuscular nicotinic or muscarinic cleft is not disturbed by the use of sugammadex.

In our patient, $150 \mathrm{mg}$ sugammadex $(2 \mathrm{mg} / \mathrm{kg}$ ) reversed neuromuscular blockade within $180 \mathrm{~s}$. He had no complications such as hypoxia, hypercapnia, or accelerated muscular weakness after extubation and without recurarization of rocuronium. Sugammadex had a rapid and efficient action in this patient with CMT as described in this case report.

Despite muscle weakness from neuromuscular dysfunction, previous studies have reported that in CMT it is difficult to monitor neuromuscular blockade using muscle relaxation monitors such as the TOF-Watch ${ }^{[5]}$. Thus, the TOF has been used to monitor muscle relaxation in the adductor pollicis and the corrugator supercilii muscles, but these values were not reproducible. Because our patient underwent orofacial surgery, it was difficult to place the electrode directly over the corrugator supercilii, so it was simply placed on the arm. However, as in previous case reports, the device was not also able to measure the exact TOFR in our case. Moreover, regardless of the clinical presence or absence of muscle weakness, the ulnar nerve may be affected in CMT patients ${ }^{[11]}$. The leading electrophysiological feature in CMT disease is an overall reduction in motor conduction velocity and to monitor neuromuscular blockade using muscle relaxation monitors could be misleading. Therefore, we carefully checked the clinical findings as a means of monitoring recovery from the effects of the muscle relaxant, such as ability to lift his head and arms, open his eyes, and protrude his tongue. We subsequently extubated the patient.

CMT is associated with several potential anesthetic risk factors such as increased sensitivity to thiopental, and hyperthermia with combined use of succinylcholine and an inhalational anesthetic ${ }^{[3,12]}$.

In conclusion, we successfully used sugammadex in a patient with CMT to reverse rocuronium-induced neuromuscular blockade during oral and maxillofacial surgery. In CMT, because muscle relaxation might not be accurately measured, clinical findings should be carefully considered in the management of anesthesia for these patients.

\section{DECLARATIONS}

\section{Acknowledgments}

The authors acknowledge the efforts of Dr. Jon Wanger in refining the final manuscript.

\section{Authors' contributions}

Concept, design: Itoh N, Hoshijima H, Takeuchi R

Definition of intellectual content: Hoshijima H, Takeuchi R, Nakamura C

Literature search: Nakamura C, Iwase Y

Clinical studies and data acquisition: Itoh N, Hoshijima H, Iwase Y, Sato T, Yoda T

Manuscript preparation and editing: Itoh N, Hoshijima H, Takeuch R

Manuscript review: Nagasaka $H$, Sato T, Yoda T

\section{Financial support and sponsorship}

None. 


\section{Conflicts of interest}

There are no conflicts of interest.

\section{Patient consent}

Obtained.

\section{Ethics approval}

Approved.

\section{Copyright}

(c) The Author(s) 2018.

\section{REFERENCES}

1. Jani-Acsadi A, Ounpuu S, Pierz K, Acsadi G. Pediatric Charcot-Marie-Tooth disease. Pediatr Clin North Am 2015;62:767-86.

2. Kurihara S, Adachi Y, Wada K, Awaki E, Harada H, Nakashima K. An epidemiological genetic study of Charcot-Marie-Tooth disease in Western Japan. Neuroepidemiology 2002;21:246-50.

3. Aboussouan LS, Lewis RA, Shy ME. Disorders of pulmonary function, sleep, and the upper airway in Charcot-Marie-Tooth disease. Lung 2007; 185:1-7.

4. Tazir M, Hamadouche T, Nouioua S, Mathis S, Vallat JM. Hereditary motor and sensory neuropathies or Charcot-Marie-Tooth diseases: an update. J Neurol Sci 2014;347:14-22.

5. Galvez-Canellas JL, Errando CL, Martinez-Torrente F, Mayor F, Zasadowski M, Villanueva Y, Soria-Bretones C. Anaesthesia and orphan disease: difficult monitoring of neuromuscular blockade in a patient with severe Charcot-Marie-Tooth disease type I. Eur J Anaesthesiol 2013;30:772-5.

6. Antognini JF. Anaesthesia for Charcot-Marie-Tooth disease: a review of 86 cases. Can J Anaesth 1992;39:398-400

7. Pasha TM, Knowles A. Anaesthetic management of a patient with Charcot-Marie-Tooth disease for staged diaphragmatic plication. Br $J$ Anaesth 2013;110:1061-3.

8. Smith JD, Minkin P, Lindsey S, Bovino B. Anesthetic and surgical management of a bilateral mandible fracture in a patient with CharcotMarie-Tooth disease: a case report. J Oral Maxillofac Surg 2015;73:1917.e1-6.

9. Pasternak JJ, Lanier WL. Diseases of the autonomic and peripheral nervous systems. In: Stoelting R, Dierdorf S, editors. Stoelting's anesthesia, coexisting disease. Philadelphia, PA: Elsevier Saunders; 2012. p. 264-73.

10. Irie T, Uekama K. Pharmaceutical applications of cyclodextrins. III. Toxicological issues and safety evaluation. J Pharm Sci 1997;86:14762.

11. Birouk N, Gouider R, Le Guern E, Gugenheim M, Tardieu S, Maisonobe T, Le Forestier N, Agid Y, Brice A, Bouche P. Charcot-MarieTooth disease type 1A with 17p11.2 duplication. Clinical and electrophysiological phenotype study and factors influencing disease severity in 119 cases. Brain 1997;120:813-23.

12. Antognini JF. Anesthetic management in Charcot-Marie-Tooth disease. Anesth Analg 1992;75:313. 